\title{
The Effect of Nd:YAG and Er,Cr:YSGG Lasers on the microhardness of Human Dentin
}

1. Wael M. Al-Omari, BDS, MDentSci, PhD

Associate Professor, Department of Restorative Dentistry, Faculty of Dentistry, Jordan University of Science and Technology, Irbid, Jordan.

2. Joseph E. Palamara, $\mathrm{BSc}, \mathrm{PhD}$

Associate Professor, School of Dental Science, Melbourne Dental School,

Faculty of Medicine, Dentistry and Health Sciences.

The University of Melbourne

720 Swanston Street,

Victoria. 3010 Australia.

Corresponding Author:

Wael. M. Al-Omari

Department of Operative Dentistry, Faculty of Dentistry, Jordan University of Science and Technology, Irbid 22110, Jordan

Telephone: 00-962-795521461

Fax Number: $\quad$ ++ 96227095115

E-Mail Addresses: womari@just.edu.jo 


\section{Introduction}

Dental clinicians are reliant on conventional drilling systems for tooth preparation and cutting diseased dental hard tissues for many decades. Although efficient, but rather painful, irritating and noisy, thus may discourage patients to accept treatment. Lasers as a potential painless comfortable alternative to mechanical cutting and drilling systems [4] have stimulated many researchers to investigate their various applications in clinical dentistry

Since the development of the ruby laser, several types of lasers have been developed and were subjected to numerous investigations. Ruby laser potential efficiency in removing carious dental hard tissues was early investigated [2]. However, because Rubby, argon, carbon dioxide $\left(\mathrm{CO}_{2}\right)$ and neodymiumdoped:yttrium-aluminum garnet (Nd:YAG) laser systems require relatively high-energy densities to ablate dental hard tissues, they usually produce subsequent major thermal side effects, such as melting, cracking, glazing, carbonisation or charring of enamel, dentin and produce excessive intrapulpal temperature [3-6]. These laser systems, despite their common application in soft tissue management procedures, were not therefore strongly recommended for common use in hard tissue treatments.

In order to minimize thermal side effects [7-9] and increase the ablation efficiency of dental hard tissues the Er:YAG and Er,Cr:YSGG laser systems [10-13] were developed with expected expanded clinical applications. 
The Er:YAG laser was found to have the ability to remove enamel and dentine efficiently and cleanly and the tissue depth, amount and volume removal were comparable with that achieved with the conventional dental drill $[6,10,11]$. The amount of tissue removal was directly proportional to the power setting $[6,14]$ and irradiation exposure time [4]. Moreover, minimal increase in pulpal temperature was produced when the Er:YAG laser was used with continuous water spray [12,15]. Laser irradiation with either Er:YAG or Er,Cr:YSGG did not also affect the hardness of dentine at a point $25 \mu \mathrm{m}$ below the cavity floor [7].

The Er,Cr:YSGG laser is a kind of erbium laser of $2780 \mathrm{~nm}$ wavelength, using a pulsedbeam system, fiber delivery, and a sapphire tip bathed in a mixture of air and water vapour. It has been reported to be effective for cutting enamel, dentine and bone $[13,16]$ and produced similar morphological changes on dentin like the Er:YAG laser [17]. It has also produced a similar calcium-to-phosphorous ratio and hardness number of the cavity floor compared to bur-cutting method $[7,18,19]$. However, in another study, dentin hardness decreased significantly after irradiation with Er,Cr:YSGG laser [14].

Water spray is used not only to suppress temperature, but also to increase cutting efficiency of Er,Cr:YSGG laser $[8,16]$. Furthermore, no pulpal inflammatory response was associated with laser preparations [11]. As an etching tool, the microtensile bond strengths of porcelain veneers bonded to tooth surfaces was reported to have similar values either treated with Er,Cr:YSGG laser or 37\% orthophosphoric acid [20]. However, 
bonding orthodontic brackets to enamel etched with Er,Cr:YSGG laser was inferior to that etched with $37 \%$ orthophosphoric acid [21].

The micromechanical properties such as microhardness play an important role in stress

distribution when the mastication forces are applied on filling material placed in a restored tooth [22] and may also affect the ability of the adhesive material to interact with the tooth surface [23]. A positive correlation between the hardness and fracture resistance of dentin was also assumed [24].

Therefore, before application of laser in the dental clinic, micromechanical properties need to be evaluated, especially as there are only few reports on the microhardness of dentinal surface prepared by Er,Cr:YSGG laser irradiation. The purpose of the current study was to investigate the effect of irradiation with Er,Cr:YSGG or Nd:YAG lasers on the microhardness of prepared dentin. The null hypothesis was that neither Er,Cr:YSGG or Nd:YAG lasers affect the microhardness of irradiated dentin.

\section{MATERIALS \& METHODS}

\section{Sample preparation}

Thirty intact third molars were used in the current study. Informed consent was obtained under a protocol reviewed and approved by the Ethics in Human Research Committee, University of Melbourne. The teeth were cleaned up of soft tissues and stored in $1 \%$ Chloramine $\mathrm{T}$ solution at $4^{\circ} \mathrm{C}$ until use. The root was sectioned $2 \mathrm{~mm}$ apical to the cemento-enamel junction (CEJ) using a slow speed diamond saw with water coolant 
(Struers, Ballerup, Denmark). The pulp was removed with tweezers then the tooth was immersed in $1 \%$ sodium hypochlorite solution (Milton's solution, Procter \& Gamble, Paramatta, NSW, Australia) and sonicated for 5 minutes for compete removal of the remaining pulp tissue.

Dentine discs were prepared by horizontal sectioning of one third of occlusal surface by means of slow speed diamond saw with water coolant (Struers, Ballerup, Denmark) resulting in a crown segment containing a portion of the pulp chamber inferiorly and flat dentine surface superiorly. The surface was visually inspected under light microscopy to ensure complete removal of enamel. Each dentine surface was finished using a 600 grit $\mathrm{SiC}$ paper under running water. The disc thickness was $2 \mathrm{~mm}$.

\section{Laser irradiation}

A square plastic block ( $4 \mathrm{~cm}$ square, $5 \mathrm{~mm}$ thick) was used to mount each tooth which was attached by means of cyano-acrylate cement (M-Bond 200, Micro-Measurement Group INC., Raleigh, NC, USA). Each tooth was clamped on a stationary stand. The laser handpiece was held on a movable stand connected to a step-motor at a distance of 1

$\mathrm{mm}$ from dentine surface. The samples were assigned into three experimental groups of ten as the following:

Group 1: The laser used in this group was Er,Cr:YSGG laser (Biolase, Waterlase Millennium, San Clement, CA, USA). This system emits photons at a wavelength of 2.78 $\mu \mathrm{m}$ with pulse duration of $140 \mu \mathrm{s}$. The repetition rate was $20 \mathrm{~Hz}$ and a power output range of 0 to $6 \mathrm{~W}$. The pulse energy varies from 0 to $300 \mathrm{~mJ}$. A G6 sapphire tip of 600 
$\mu \mathrm{m}$ diameter was used. The handpiece was moved horizontally along the mesio-distal plane of the tooth. At the end of each laser line path the handpiece was moved vertically in a bucco-lingual plane at an interval of $200 \mu \mathrm{m}$ and then moved at the disto-mesial direction. The repetition line was made automatically at back and forth direction until one half of the exposed surface is irradiated. The total laser time was about 2 minutes. The teeth were treated with $3.5 \mathrm{~W}$ setting (70\% water, $60 \%$ air).

Group 2: The same as group 1, except that the teeth were treated with $4.5 \mathrm{~W}$ power output (70\% water, $60 \%$ air).

Group 3: The laser used for this group was a Nd:YAG laser (American Dental Laser dLase 300, Sunrise Technologies Inc., Ca, USA) containing a $320 \mu \mathrm{m}$ diameter optical fiber. The repetition rate was set to $20 \mathrm{~Hz}$ with $2 \mathrm{~W}$ power output. To enhance energy absorption, black ink was applied to the tooth surface before each lasing [25]. The procedure was followed as in group $1 \& 2$, except that the laser lines were at an interval distance of $300 \mu \mathrm{m}$.

\section{Microhardness measurement:}

Surface microhardness measurements were performed using Vickers indentor attached to a microhardness tester (MTH-10 Microhardness Tester, Anton Paar GmbH, Graz, Austria). Twenty indentations were made on the sound untreated dentine disc half which served as control and other twenty indentations on the laser treated half of each sample. The indentation load was $100 \mathrm{~g}$ with $10 \mathrm{~s}$ dwell time with at least $300 \mu \mathrm{m}$ between successive indentations. As a distance of at least two times the impression diagonal for 
dentine should be kept between the indentations to minimize interaction between neighboring indentations [26].

Subsurface hardness was measured by increasing the indentation load to penetrate the laser treated layer into the sound unaffected subsurface layer of dentine. Loads of 200 and $300 \mathrm{~g}$ were found not large enough to penetrate the entire thickness of the laser affected layer. The indentation was inspected under magnification under light microscopy and if the lased dentine appeared rolled over on the margins and sound dentinal tubules could be visualized within the pyramidal-indentation area, it was concluded that the load has been readily applied onto the sound subsurface area. A load of $400 \mathrm{~g}$ with $10 \mathrm{~s}$ dwell time was selected.

Ten indentations per laser treated surface at a load of $400 \mathrm{~g}$ and dwell time of $10 \mathrm{~s}$ were made. The depth of the laser affected layer of dentine was calculated from the following equation for Vickers indenter [27]:

$$
\begin{gathered}
\mathrm{A}=4 \mathrm{~h}_{\mathrm{p}}{ }^{2} \tan ^{2} \theta \\
\mathrm{A}=(\mathrm{d} 1+\mathrm{d} 2 / 2)^{2} / 2
\end{gathered}
$$

Where $A$ is projected area, $\mathrm{d} 1 \& \mathrm{~d} 2$ are the length of diagonals of the indent, $\theta=68, \mathrm{~h}_{\mathrm{p}}=$ the plastic depth of the indent.

\section{Statistical Analysis}

Surface and subsurface Vicker's hardness of various groups were compared using oneway ANOVA at a significant level of 0.05 followed by a Tukey's Studentized post hoc 
test. Paired t test was used to compare the hardness of laser treated surface with untreated dentine surfaces for each group.

\section{Results}

The average values of Vicker's hardness number (VHN) of surface dentine for the baseline and post-irradiation are shown in Table 1. Surface hardness values of sound dentine (baseline) were not significantly different among the experimental groups (ANOVA, $\mathrm{p}=0.25$ ). However, dentine surface hardness decreased significantly after laser irradiation with either Nd:YAG or Er,Cr:YSGG laser ( $\mathrm{t}$ test, $\mathrm{p}<0.05$ ). The surface hardness values of irradiated dentine were significantly different among experimental groups. The surfaces irradiated with $3.5 \mathrm{~W}, \mathrm{Er}, \mathrm{Cr}$ :YSGG laser were significantly softer than surfaces irradiated with 4.5 W Er,Cr:YSGG laser and Nd:YAG, $2 \mathrm{~W}$ power output. There were significant differences among all the groups (ANOVA, $\mathrm{p}<0.05$ ).

The surface hardness values measured with load of $4 \mathrm{~N}$ (subsurface hardness) are illustrated in Table 1. There were no significant differences between the groups and neither between the subsurface hardness and the baseline surface hardness. The Hp value, related to load $4 \mathbf{N}$, which is considered as the average thickness of laser irradiated layer was $15.5 \mu \mathrm{m}$ for all the groups. A significant correlation was found between the increasing hardness and $\mathrm{Hp}$ value $\left(\mathrm{R}^{2}=.18, \mathrm{p}<0.05\right)$. 


\section{Discussion}

Hardness is the resistance of the material to indentation and it is a property directly related to susceptibility of a material to deformation and fracture. The micromechanical properties such as microhardness of irradiated human teeth should be thoroughly investigated for a better understanding that would possibly improve clinical treatment of tooth fracture and predict susceptibility of teeth to fracture [24, 26].

The mean hardness of mineralized dentin found in this study was in accordance with previously reported values ranging from 50 to 70 [28]. In the current study both Nd:YAG and Er,Cr:YSGG laser irradiation had significantly reduced the hardness of irradiated dentine, thus the null hypothesis was rejected. The degree of reduction in microhardness was also dependent on the power output of the Er,Cr:YSGG laser used. The use of higher power output with Er,Cr:YSGG laser resulted in dentin surfaces of significantly greater microhardness values (Table 1).

The response of target tissues to laser may be affected by various irradiation parameters but mainly on the distribution of the laser energy within the irradiated object. If the energy source is high enough it will heat up the irradiated dentine to a point where melting, charring and recrystallization occurred despite the fact that the incident energy is partially dispersed in or reflected off the targeted dentinal surface. It was concluded that Nd:YAG may raise the temperature on the dentine surface to more than $1125^{\circ} \mathrm{C}$ [29].

However, decomposition of pure hydroxyapatite, the main mineral content of the inorganic components of dentine, has been reported to occur at a temperature up to 1500 
${ }^{\circ} \mathrm{C}$ causing multiple cracks [26]. On the other hand, it was found that heating dental hard tissues to a temperature of more than $400{ }^{\circ} \mathrm{C}$ causes decomposition of mineral components and form a new mineral phase that may enhance the resistance to acid dissolution [9].

Providing that $20 \%$ of dentin is a collagen matrix [30] and that collagen bundles contribute to increasing resistance of dentine to crack propagation and relieving stress [31], it was postulated that the high temperature produced by Nd:YAG irradiation could have vaporized the organic matrix, such as collagen, leaving pores and voids that are responsible for the significant reduction in hardness [26]. This could explain the findings of the current investigation which concurs with previous findings [26,32]. However, the hardness of dentin has been reported to have increased after irradiation with Nd:YAG laser and was explained by the melting and resolidification of dental hard tissues [33]. Moreover, the effect on hardness could have been related to alteration in mineral content and compositional features of irradiated dental hard tissues [9] as a correlation between mechanical properties and mineral contents in tooth structure was established [33]. It was found that after Nd:YAG irradiation, $\mathrm{Ca} / \mathrm{P}$ ratio was low when compared to nonirradiated dentine [4], which might contribute to the progressive deterioration of the dentine hardness after laser irradiation that was observed in the current and previous studies $[26,32]$.

Unlike Nd:YAG laser, the Er,Cr:YSGG laser is a hydrokinetic system where ablation is water-mediated, and flooding the cutting tip with a spray of water minimizes the 
generated heat $[8,13,14,16]$. And unlike the use of shorter wavelengths of the Nd:YAG $(1,064 \mathrm{~nm})$ laser which have no appreciable absorption in dental hard tissue, and can lead to thermal cracking and amorphous change in the hydroxyapatite crystal structure, the erbium wavelengths have a considerable affinity for hydroxyapatite and water chromophores.

The Er,Cr:YSGG laser cutting mechanism is called "thermomechanical process" in which emitted laser pulsed-wave is readily absorbed by the water in the hydroxyapaptite of enamel and dentine and caused the vaporisation of the heated water and other hydrated organic components [8]. Vaporisation results in increased internal pressure within the target tissues that eventually caused instantaneous microexplosions that destroy the inorganic components before the melting point of tooth tissue and leads to ejection of micro-fragments [4].

In contrast to $\mathrm{Nd}$ :YAG laser, Er,Cr:YSGG laser-treated surfaces demonstrated microirregularities, corrugated or wavy profile, opened protruded dentinal tubules due to preferential ablation of the less mineralized intertubular dentin, absence of smear layer and also an absence of thermal changes such as melting or carbonation $[7,14$ 17,34,35]. At low power parameter, dentin debris was observed with tags attaching it to the underlying lased dentin [14]. Moreover, it was found that the glassy molten substance without any debris on the dentinal surfaces ablated at high power settings were composed of the same elements as hydroxyapatite [13-14]. This was claimed to indicate that dentine constituents undertake thermoplastic properties as the molten heated 
elements may immediately return to solid state apparently enhanced by water cooling [13].

The high absorption of Er,Cr:YSGG laser wavelength by the water rich collagen fibers and hydroxyapatite causes simultaneous ablation, besides rapid heating of the mineral contents, contributes to the explosive dissociation of the target hard tissue [9] and might be responsible for the reduction of hardness of irradiated dentine in the current investigation. The findings are in agreement with previous study where the dentine hardness was significantly reduced after irradiation with Er,Cr:YSGG laser irrespective of the power setting [13]. Similarly, it was found that the laser power setting did not considerably affect the extent of reduction in microhardness although was directly proportional to amount of ablation [13]. However, the current findings revealed that the lower power setting $(3.5 \mathrm{~W})$ of Er,Cr:YSGG laser reduced the hardness more than the higher power setting of $4.5 \mathrm{~W}$. Probably the higher power may have induced more pronounced thermal effect, although minimized by the water spray, which probably resulted in rapid recrystallization similar to the effect produced by $\mathrm{Nd}: \mathrm{YAG}$ laser. Thermal effect produces resolidified surfaces with an increased hardness.

Contrary to the findings of the current investigation, it was reported that Er,Cr:YSGG laser irradiation did not affect the hardness of the cavity floors compared to bur prepared cavities $[17,18]$. However, unlike the current investigation, in the previous studies, the cavity floor microhardness was measured at point $25 \mu \mathrm{m}$ [10] and $50 \mu \mathrm{m}$ [18] below the cavity floor. Hence, the findings of Hossain et al. [17] and Celik et al. [18] of non- 
significant differences between the irradiated and bur cut surfaces could be misleadingly interpreted, because the hardness measurement were not made for the outmost laseraffected layer [26].

Based on the current findings, the indentor loading force of $4 \mathrm{~N}$ was employed, based on the pilot study, to penetrate into the laser-unaffected subsurface zone. The plastic depth of the indent was $15.5 \mu \mathrm{m}$ for all laser groups. This may represent the critical depth of laser irradiation influencing the microhardness of dentine. That critical depth was about 7 $\mu \mathrm{m}$ for Nd:YAG laser as reported by Lee and co-workers [26]. However, different laser parameters were used, thus direct comparison cannot be accurately made.

Generally, it is difficult to compare the varied results obtained from the different studies due to the wide diversity in the type of laser energy, power parameters and presence or absence of water cooling that may render them incomparable.

\section{Conclusions}

Within the limitations of the current study, both laser systems used have reduced the microhardness of irradiated dentine significantly compared to the control. Increasing the power setting of Er,Cr:YSGG laser seems to increase the hardness of dentine in a comparable extent to the thermal effect of Nd:YAG. The Er,Cr:YSGG laser reduced the hardness of dentine significantly more than Nd:YAG laser. Further studies are needed to understand the mechanism that affected the mechanical properties of irradiated dentine. It 
was also concluded that the microhardness measurement should be recorded for the most superficial laser-affected layer to report realistic findings.

\section{References.}

1- Wigdor H, Abt E, Ashrafi S \& Walsh JT (1993) The effect of lasers on dental hard tissues. J Am Dent Assoc 124:65-70.

2- Goldman L, Hornby P, Meyer R, Goldman B (1964) Impact of the laser on dental caries. Nature 25 (203): 417.

3- Goldman L, Gray JA, Goldman J, Goldman B, Meyer R (1965) Effect of laser beam impacts on teeth. J Am Dent Assoc 70: 601-606.

4- Kim KS, Kim ME, Shin EJ (2005) Irradiation time and ablation rate of enamel in contact and non-contact irradiation with Er:YAG laser. Photomed Laser Surg $23: 216-218$.

5- Frentzen M, Koort HJ (1990) Lasers in dentistry: New possibilities with advancing laser technology?. Int Dent J 40:323-332.

6- Mehl A, Kremers L, Salzman K, Hickel R (1997) 3D volume-ablation rate and thermal side effects with the Er:YAG and Nd:YAG laser. Dent Mater 13:246-251.

7- Eversole LR, Rizoiu I, Kimmel AI (1997) Pulpal response to cavity preparation by an erbium,chromium:YSGG laser-powered hydrokinetic system. J Am Dent Assoc 128:1099-106.

8- Rizoiu I, Kohanghadosh F, Kimmel AI, Eversole LR (1998) Pulpal thermal responses to an erbium, chromium: YSGG pulsed laser hydrokinetic system. Oral Surg Oral Med Oral Pathol Oral Radiol Endod 86:220-223. 
9- Fried D (2000) IR laser ablation of dental enamel. Proc SPIE 3910:136-148.

10- Hibst R, Keller U (1989) Experimental studies of the application of the Er:YAG laser on dental hard substances: I. Measurement of the ablation rate. Lasers Surg Med 9:338-344.

11- Keller U, Hibst R (1989) Experimental studies of the application of the Er:YAG laser on dental hard substances. II. Light microscopic and SEM investigations. Lasers Surg Med 9:345-351.

12- Hossain M, Nakamura Y, Yamada Y, Kimura Y, Nakamura G, Matsumoto K (1999) Ablation depths and morphological changes in human enamel and dentin after Er: YAG laser irradiation with or without water mist. J Clin Laser Med Surg 17:105-109.

13- Hossain M, Nakamura Y, Yamada Y, Kimura Y, Matsumoto N, Matsumoto K (1999) Effects of Er,Cr:YSGG laser irradiation in human enamel and dentin: ablation and morphological studies. J Clin Laser Med Surg 17:155-159.

14- Ekworapoj P, Sidhu SK, McCabe JF (2007) Effect of different power parameters of Er, Cr:YSGG laser on human dentin. Lasers Med Sci 22:175-182.

15- Visuri SR, Gilber JL, Wright DD, Wigdor HA, Walsh JT (1996) Shear strength of composite bonded to Er:YAG laser-prepared dentin. J Dent Res 75:599-605.

16- Harashima T, Kinoshita J, Kimura Y, Brugnera A, Zanin F, Pecora JD (2005) Morphological comparative study on ablation of dental hard tissues at cavity preparation by Er:YAG and Er,Cr:YSGG lasers. Photomed Laser Surg 23:52-55. 
17- Hossain M, Nakamura Y, Tamaki Y, Yamada Y, Murakami Y, Matsumoto K (2003) Atomic analysis and knoop hardness measurement of the cavity floor prepared by Er,Cr:YSGG laser irradiation in vitro. J Oral Rehabil 30:515-21.

18-Çelik EU， Ergücü Z, Türkün LS, Türkün M (2008) Effect of Different Laser Devices on the Composition and Microhardness of Dentin. Oper Dent 33:496501.

19- Shahabi S, Zendedel S (2010) Atomic analysis and hardness measurement of the cavity prepared by laser. Lasers Med Sci 25:379-83.

20- Usumez A, Aykent F (2003) Bond strengths of porcelain laminate veneers to tooth surfaces prepared with acid and Er, Cr:YSGG laser etching. J Prosthet Dent 90:24-30.

21-Usumez S, Orhan M, Usumez A (2002) Laser etching of enamel for direct bonding with an Er, Cr:YSGG hydrokinetic laser system. Am J Orthod Dentofacial Orthop 122:649-56.

22- Fuentes V, Ceballos L, Osorio R, Toledano M, Carvalho RM, Pashley D (2004) Tensile strength and microhardness of treated human dentin. Dent Mater 20:522529.

23- Yoshiyama M, Tay FR, Doi J, Nishitani Y, Yamada T, Itou K, Carvalho RM, Nakajima M, Pashley DH (2002) Bonding of self-etch and total-etch adhesives to carious dentin. J Dent Res 81:556-560.

24- Perinka L, Sano H, Hosoda H (1992) Dentin thickness, hardness, and Caconcentration vs. bond strength of dentin adhesives. Dent Mater 8:229-233. 
25- Arcoria CJ, Lippas MG, Vitasek BA (1993) Enamel surface roughness analysis after laser ablation and acid etching. J Oral Rehabil 20:213-214.

26- Lee BS, Lin CP, Lin FH, Li UM, Lan WH (2003) Effect of Nd:YAG laser irradiation on the hardness and elastic modulus of human dentin. J Clin Laser Med Surg 21:41-49.

\section{7-Anthony C. Fisher-Cripps AC (2004) Nanoindentation (Mechanical} Engineering Series), 2nd edn. Springer, New York, p26.

28- Meredith N, Sherriff M, Setchell DJ, Swanson SA (1996) Measurement of the microhardness and Young's modulus of human enamel and dentine using an indentation technique. Arch Oral Biol 41:539-345.

29- Lin CP, Lee BS, Lin FH, Kok SH, Lan WH (2001) Phase, compositional, and morphological changes of human dentin after Nd:YAG laser treatment. J Endod 27:389-393.

30- Angker L, Swain MV, Kilpatrick N (2005) Characterising the micro-mechanical behaviour of the carious dentine of primary teeth using nano-indentation. $\mathrm{J}$ Biomech 38:1535-1542.

31-Lin CP, Douglas WH (1994) Structure-property relations and crack resistance at the bovine dentin-enamel junction. J Dent Res 73:1072-1078.

32- Kuramoto M, Matson E, Turbino ML, Marques RA (2001) Microhardness of Nd:YAG laser irradiated enamel surface. Braz Dent J 12:31-33.

33- Marquez F, Quintana E, Roca I, Salgado J (1993) Physical-mechanical effects of Nd:YAG laser of sound dentine and enamel. Biomaterials 14:313-316. 
34- Rohanizadeh R, Legeros RZ, Fan D, Jean A, Daculsi G (1999) Ultrastructural properties of laser-irradiated and heat treated dentin. J Dent Res 78:1829-1835

35- Carvallo AO, Reis AF, de Oliveira MT, de Freitas PM, Aranha AC, Eduardo CP, Giannini M (2011) Bond strength of adhesive systems to ER, Cr:YSGG laser-irradiated dentin. Photomed Laser Surg 29:747-752. 
Table 1: The means (SD) of Vicker's micro-hardness, subsurface hardness and Hp (in Micrometer) value.

\begin{tabular}{ccccc}
\hline \multicolumn{1}{c}{ group } & baseline & $\begin{array}{c}\text { Hardness } \\
(\text { Load 1 N) }\end{array}$ & $\begin{array}{c}\text { Hardness } \\
(\text { Load 4N) }\end{array}$ & $\begin{array}{c}\text { Depth of } \\
\text { Indent (Hp) } \\
(\text { Load 4) }\end{array}$ \\
\hline Biolase-3.5 W & $65.26(7.89)$ & $39.02(7.81)^{*}$ & $64.35(8.7)$ & 15.58 \\
Biolase 4.5 W & $66.54(7.57$ & $43.50(8.36)^{*}$ & $63.61(8.29)$ & 15.54 \\
Nd-YAG & $65.83(7.48)$ & $57.07(10.37)^{*}$ & $65.3(7.28)$ & 15.53 \\
\hline
\end{tabular}

* Significant difference. 